\title{
Rendimiento diagnóstico del agar sangre con filtro versus agar karmali para el diagnóstico de Campylobacter en coprocultivo
}

\author{
Jeel Moya-Salazar ${ }^{1}$, Liz Pio-Dávila², Alfonso Terán-Vásquez³ ${ }^{3}$ José Olivo-López ${ }^{4}$
}

RESUMEN

Objetivo: Evaluar el rendimiento diagnóstico del agar sangre con filtro (ASF) en comparación con el agar Karmali (AK) para el diagnóstico de Campylobacter spp en coprocultivo.

Material y métodos: Se realizó una investigación de tipo experimental prospectiva de corte transversal en el Hospital Nacional Docente Madre-Niño "San Bartolomé" se evaluaron muestra de heces con examen coprológico funcional reactivo para inflamación. Las muestras fueron sembradas en ASF y en AK e incubadas hasta 72 horas en microaerofilia. La diferenciación de especies se realizó con la hidrolisis de hipurato.

Resultados: Se recolectaron un total de 287 muestra positivas. El aislamiento de Campylobacter en ASF y AK fue de 78, 3\% y $21,7 \%$, respectivamente. La sensibilidad fue de $90,9 \%$ para ASF. El tiempo de crecimiento promedio fue de $32,7 \pm 11$ horas $(\mathrm{p}<0,59)$ y la contaminación de medios de cultivo de pacientes positivos fue de $61,7 \%$ para AK. Se aislaron un $74,8 \%$ de especies de Campylobacter no jejuni.

Conclusiones: el Agar Sangre con filtro presenta un mayor rendimiento diagnóstico que Agar Karmali para el aislamiento de Campylobacter, en un tiempo relativamente menor y demostrando ser más costo-efectivo que el medio de asilamiento selectivo. Además, se aisló principalmente Campylobacter no jejuni en neonatos e infantes, donde acontecen la mayoría de infecciones.

Palabras clave: campylobacter, agar, sangre, diarrea, agar karmali, diagnóstico.

\section{Diagnosis yield of blood agar with filter against karmali agar for isolation of Campylobacter in stool culture}

\section{ABSTRACT}

Objective: To evaluate the diagnostic yield of blood agar with filter (BAF) compared to Karmali agar (KA) for the isolation of Campylobacter spp in stool culture.

Material and methods: A prospective cross section experimental investigation was performed at "San Bartolome" MotherChild Teaching National Hospital. Stool samples were evaluated with a reactive functional stool test for inflammation. Samples were inoculated in BAF and KA and incubated for up to 72 hours in microaerophilic conditions. Sample differentiation was performed by the Hippurate hydrolysis test.

Results: A total of 287 positive samples were collected. The isolation of Campylobacter in BAF and KA were of the order of $78.3 \%$ and $21.7 \%$, respectively. The sensitivity was $90.9 \%$ for BAF. The average growth time was $32.7 \pm 11$ hours $(p<0.59)$ and the contamination of culture media from positive patients was of the order of $61.7 \%$ for KA. $74.8 \%$ of the isolated species were Campylobacter non- jejuni.

Conclusions: BAF has a higher diagnostic yield than KA for the isolation of Campylobacter in a relatively shorter time providing to be more cost-effective than selective isolation. In addition, Campylobacter non-jejuni was mainly isolated in neonates and infants, where most infections occur.

Key words: campylobacter, agar, blood, diarrhea, karmali agar, diagnosis.

1. MSc(c), M.T., Facultad de Ciencias y Filosofía, Universidad Peruana Cayetano Heredia, Lima, Perú.

2. MLT., Hospital Nacional Dos de Mayo, Lima, Perú.

3. M.Ed., MLT., Área de Microbiología, Hospital Nacional Docente Madre-Niño San Bartolomé, Lima, Perú.

4. M.T., Servicio de Microbiología. Instituto Nacional de Salud del Niño, Lima, Perú. 


\section{INTRODUCCIÓN}

La enfermedad diarrea aguda (EDAs o ADD en inglés) es una de las cuatro principales causas de mortalidad infantil y una de las tres que tienen relación con el cambio climático ${ }^{(1)}$. Durante el 2015 1,2 millones de muertes fueron por enfermedades diarreicas o trastornos afines aproximadamente, $80 \%$ de estas en infantes durante los primeros 2 años de vida ${ }^{(2)}$. Representan el $15 \%$ de todas las muertes en niños menores de 5 años en países con bajo grado de desarrollo donde están relacionados hasta en un $88 \%$ con deficiencias en el abastecimiento de agua, saneamiento inadecuado y mala higiene comunitaria $^{(3,4)}$.

Esta afección ocasiona alteraciones en el desarrollo humano en tres aspectos fundamentales: limitaciones en el crecimiento orgánico, disminución del capital intelectual e incremento de los Años Vida Saludablemente Perdidos (AVISA o DALY en inglés).

Una de las principales causas de ADD son las infecciones por Campylobacter. Esta bacteria capnófila es causante del alto porcentaje de gastroenteritis en el mundo entero, en todos los grupos de edad y con mayor incidencia en niños menores de cinco años, coincidiendo en prevalencia con Salmonella y Shigella ${ }^{(5,6)}$.

El riesgo atribuible de transmisión a humanos es de $41 \%$, la infección está implicada con el consumo de aves de corral, principalmente pollos, en un $80 \%$, aunque no exclusivamente. El $20 \%$ restante se asocia al medio ambiente, inmunidad y factores socioeconómicos ${ }^{(7,8)}$. El 2010 la tasa de incidencia global fue de 13.6 casos por cada 100,000 habitantes en los Estados Unidos de América ${ }^{(9)}$.

La presentación cínica es variable, desde diarrea acuosa hasta disentería. También se han observado, con diverso grado de frecuencia, complicaciones como bacteriemia, hepatitis, abortos y pancreatitis.

Entre las principales complicaciones postinfección figuran la artritis reactiva y trastornos neurológicos como el síndrome de Guillain-Barré ${ }^{(10,11)}$.

Los primeros aislamientos de Campylobacter fueron de hemocultivos, medio nutricio libre de competencia bacteriana, lo que hacía viable su aislamiento. Completamente distinto a los aislamientos en coprocultivo, donde las bacterias que compiten en crecimiento con Campylobacter y los múltiples requerimientos para su aislamiento son problemas usualmente comunes. Con el fin de evitar crecimientos de coliformes contaminantes primero Dekeyser, luego Skirrow, idearon filtrar las muestras de heces diarreicas a través de membranas de filtros con porosidad de $0,5 \mu \mathrm{m}$, lo cual permitía retener a la mayoría de bacterias presente en las muestras pasando solo bacterias muy delgadas como Campylobacter ${ }^{(12)}$. Sin embargo, la falta de esterilidad al momento de utilizar y remover el filtro de membrana ocasionaron contaminación micótica y bacteriana. Por el contrario, los medios formulados en base a antibióticos, usados inicialmente por Bützler mejoraron el aislamiento de Campylobacter al inhibir el crecimiento de otros agentes ${ }^{(13)}$. El desarrollo posterior del Agar Bützler, una combinación de agar sangre con base de medio Brucella o agar Campylobacter con la adición de cinco antibióticos (novobiociona, bacitracina, colistina, cefazolina y cicloheximida), aumento el aislamiento de Campylobacter ${ }^{(14)}$. Posteriormente Skirrow ideo otra fórmula más simple con solo tres antibióticos (vancomicina, polimixina $B$ y trimetropina ambos conocidos como suplemento B y $S$, respectivamente) ${ }^{(15)}$.

Actualmente, estos medios de cultivo han sufrido modificaciones en sus presentaciones comerciales, generalmente con aumento de antibióticos como colistina-sulfato, novobiocina y bacitracina: Skirrow (Oxoid, Wade Road, UK), también con adición de suplemento selectivo de piruvato sódico y hemina en el agar base Karmali(16). Aun así, los agentes contaminantes continúan dificultando el aislamiento de Campylobacter, al parecer no son inhibidos por los antibióticos empleados y por consiguiente, obtienen más nutrientes que Campylobacter, dificultando su aislamiento.

Además, estas metodologías en coprocultivo entran a una disconformidad entre costo-efectividad, siendo poco efectivos los medios de aislamiento comerciales $\mathrm{y}$, según algunos autores y guías, hay mejor aislamiento con el agar sangre o agar Campylobacter con filtro de membrana ${ }^{(17)}$. Por ello es conveniente evaluar el rendimiento diagnóstico y tiempo de crecimiento en estos medios de cultivo, para poder seleccionar el mejor performance que proporcione aislamientos viables, en poco tiempo de procesamiento y buen costo de efectividad y eficacia.

El objetivo del presente estudio fue evaluar el rendimiento diagnóstico del agar sangre con filtro en comparación con el agar Karmali para el diagnóstico 
de Campylobacter spp en coprocultivo. Asimismo, evaluar la frecuencia de asilamiento de Campylobacter jejuni y de contaminación de los agares.

\section{MATERIAL Y MÉTODOS}

Se realizó una investigación de tipo experimental prospectiva de corte transversal en el área de Microbiología del Servicio de Patología Clínica del Hospital Nacional Docente Madre-Niño "San Bartolomé" en Lima, Perú. El estudio tuvo la aprobación del Comité de Ética e Investigación del Departamento de Apoyo a la Investigación del Hospital.

El tamaño muestral fue calculado usando EPIDAT 4.1 (Xunta de Galicia, España) considerando una sensibilidad de 0,95, una heterogeneidad de 50\% y una precisión de 0,04 obteniéndose un tamaño muestral de 201 pacientes (recién nacidos y hasta los 24 meses de edad). Las muestras fueron derivadas desde consultorios externos o del área de parasitología con reacción inflamatoria para el estudio de coprocultivo. Se excluyeron los pacientes mayores de dos años, las muestras de heces colectada sin completar los requisitos mínimos de calidad, heces sólidas, no conservadas, de más de cuatro o seis horas respecto al muestreo o en evidentemente contaminadas.

Técnica de recolección de datos y procesamiento de la muestra

Etapa pre analítica: Las muestras de heces fueron colectadas en torundas húmedas en neonatos, en frascos de plástico o viales estériles por los tutores o enfermeras de los pacientes ${ }^{(18,19)}$. Estas, fueron remitidas al servicio de microbiología donde se codificaron. Las muestras de heces obtenidas fueron evaluadas para reacción inflamatoria siendo las positivas derivadas para coprocultivo. Las muestra fueron conservadas en el sistema de Colección y transporte BBL Culture Swab ${ }^{m}$ Plus (BD, Le Pont de Claix, France) o agar Amies (Oxoid, Wade Road, UK), a temperatura ambiente hasta su evaluación en forma conjunta $^{(20)}$. Se excluyeron muestras preservadas cuyo indicador estuvo virado indicando falla del sistema buffer.

Se registró el código de recepción al Libro de ingresos de casos diarios siguiendo la numeración del servicio sobre las placas Petri y sobre la hoja de trabajo FlokChek.
Etapa analítica: Las muestras se procesaron frescas, dentro de las 2 horas respecto a la colección con el fin de evitar sobrecrecimiento de la flora normal que puede enmascarar o destruir a los enteropatógenos, y correctamente ambientadas como lo recomiendan en diferentes manuales ${ }^{(21-24)}$. Los medios de cultivo se incubaron en estufa a $37^{\circ} \mathrm{C}$ durante 2 horas pre-sembrado para eliminar el exceso de líquido de condensación y las muestra se homogenizaron agitándose por inversión y con movimientos circulares. El cultivo realizó en paralelo en Agar Sangre Ovina al 5\% (Merck, Darmstadt, Germany) con filtro (ASF) de membrana grid GN-6 Metricel $^{\circledR}$ $0.45 \mu \mathrm{m}, 47 \mathrm{~mm}$ (PALL, NY, USA); y en Agar Karmali (AK) (Merck, Darmstadt, Germany) e incubadas a $42^{\circ} \mathrm{C}$ durante 72 horas en microaerofilia $\left(5 \% \mathrm{O}_{2}\right.$, $10 \% \mathrm{CO}_{2}$ y $\left.85 \% \mathrm{~N}_{2}\right)^{(25-27)}$. Se utilizaron cepas de Campylobacter jejuni ATCC 33291, a las mismas condiciones, como control de calidad del estudio.

Lectura de Cultivos: Después de 12, 48 y 72 horas se revisaron las placas, examinadas bajo una potente fuente de luz que permitió observar con claridad las colonias hasta en tres tipo de morfología distintas: a) grisáceas, secas o húmedas, y planas de forma irregular; b) grisáceas, redondeadas, convexas y brillantes con bordes definidos; y c) colonias grisáceo-verdoso húmedas de bordes irregulares ${ }^{(28)}$. La presencia o ausencia de Campylobacter se determinó por medio de una relación entre el aspecto y la cantidad de colonias sospechosas con morfología y características propias de la colonia, por ello se realizó un extendido y coloración de Gram interrumpido para verificar la morfología bacteriana por microscopia: formas espiraladas curvas en forma de "ala de gaviota" Gram negativas. Los cultivos con ausencia de crecimiento se mantuvieron hasta las 96 horas para considerarlos como negativos. La diferenciación de especies se realizó con hidrolisis de hipurato y la visualización de púrpura de Ruhemann ${ }^{(29)}$.El antibiograma se realizó siguiendo los procedimientos de la guía CLSI M100-S22 y M45-A2 por Disco difusión ${ }^{(30,31)}$.

Etapa post analítica: Los resultados fueron digitados en el libro de reportes del servicio, previa validación del personal de laboratorio y entregados a los pacientes en los tiempos estipulados. 
Técnica de análisis estadístico: El análisis estadístico fue mediante IBM SPSS v20.0 (Armonk, USA), para Windows. Para la comparación de la sensibilidad de ASF y AK se utilizó la prueba de Chicuadrado, considerando como estándar de referencia el coprocultivo en AK. Para la comparación de los tiempos de crecimiento se utilizó la prueba de $t$ de Students para muestras relacionadas. Se consideró un valor de $\mathrm{p}<0,05$ como estadísticamente significativo.

\section{RESULTADOS}

Se incluyeron un total de 287 muestras de heces. La mediana de la edad de los pacientes fue de 9,00 , con un promedio de 8,92 meses de edad, considerando al neonato como un mínimo y un máximo de 24 meses. 219 muestras $(76,3 \%)$ presentaron reacción inflamatoria positiva, principalmente por presencia de linfocitos fecales y abundante mucosidad ${ }^{(32)}$.

Rendimiento diagnóstico: Para ASF 180 (78,3\%) tuvieron cultivo positivo, resultado que varía significativamente de $A K(p=0.12)$ (Tabla 1) La sensibilidad encontrada para ASF fue de $90,9 \%$ (índice $\mathrm{J}$ de Youden de 0,2$)^{(33)}$. Todos los cultivos positivos de AK también presentaron crecimiento en ASF, ningún cultivo negativo en ASF presentó crecimiento en AK.

Tabla 1. Epitome de Rendimiento diagnóstico $(n=287)$

\begin{tabular}{lcccc}
\hline \multirow{2}{*}{ ASF } & \multicolumn{5}{c}{ AK } \\
\cline { 2 - 5 } & Positivo & Negativo & Contaminado & Total \\
\hline Positivo & 23 & 15 & 142 & 180 \\
Negativo & 27 & 70 & 9 & 110 \\
Contaminado & 0 & 0 & 1 & 1 \\
Total & 50 & 85 & 152 & 287 \\
\hline
\end{tabular}

Cuando se evaluó la contaminación de cultivos 121 muestras $(53,6 \%)$ en $A K$ estuvieron parcial o totalmente contaminadas, variando considerablemente con ASF (Tabla 1). Así, el aislamiento de Campylobacter jejuni y Campylobacter no-jejuni fue de 42(18\%) y 138 (60\%) para ASF y $16(7 \%)$ y $34(15 \%)$ para AK, respectivamente (Figura 2).

Figura 2. Aislamiento de Campylobacter jejuni y Campylobacter no-jejuni en AK y ASF

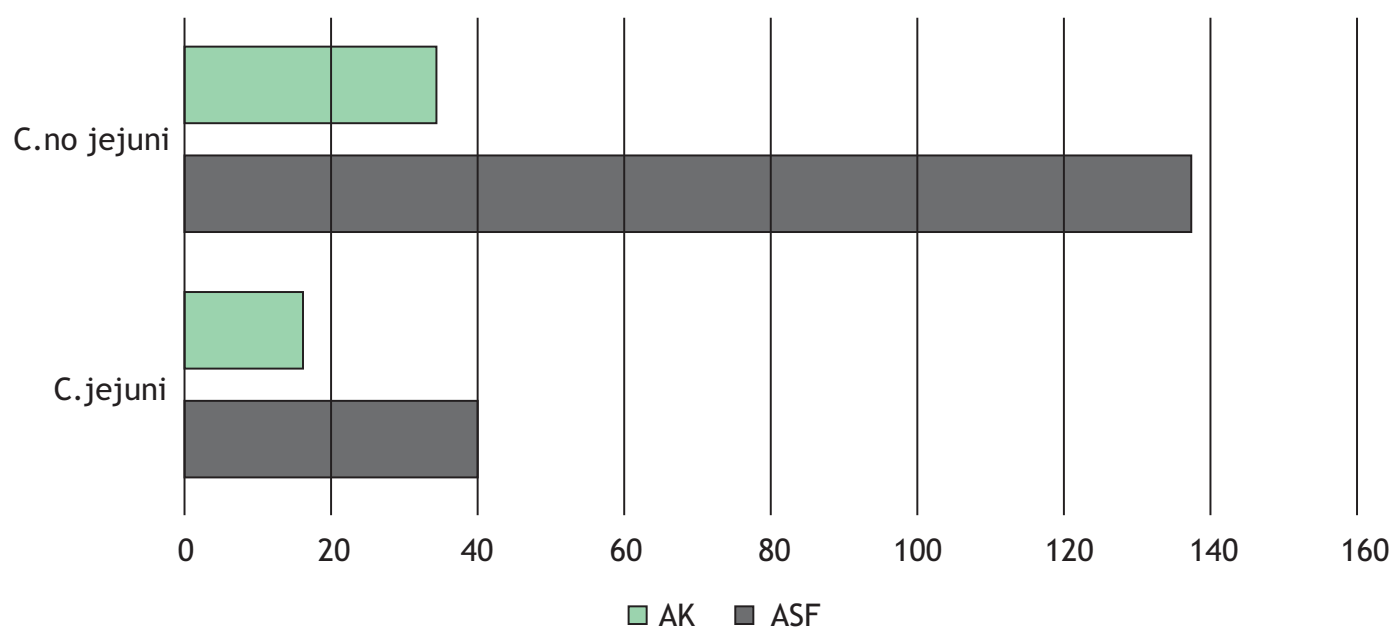

El tiempo promedio de crecimiento para Campylobacter en AK y ASF fue de 34,56 y 33,13 (Tabla 3). No se encontró diferencia significativa para los tiempos de crecimiento entre ambos medios de cultivo $(p=0,59)$. 
Rendimiento diagnóstico del agar sangre con filtro versus agar

karmali para el diagnóstico de Campylobacter en coprocultivo

Tabla 2. Tiempo de crecimiento: aislamiento primario

\begin{tabular}{ccccc}
\hline $\begin{array}{c}\text { Medio de } \\
\text { cultivo }\end{array}$ & $\begin{array}{c}\text { Tiempo de } \\
\text { crecimiento (horas) }\end{array}$ & $\begin{array}{c}\text { Mínimo } \\
\text { (horas) }\end{array}$ & $\begin{array}{c}\text { Máximo } \\
\text { (horas) }\end{array}$ & IC 95\% \\
\hline ASF & $34,56 \pm 12,2$ & 10 & 48 & 29,54 a 39,58 \\
AK & $33,13 \pm 11,7$ & 20 & 50 & 30,35 a 35, 90 \\
\hline
\end{tabular}

Figura 1. Crecimiento de Campylobacter spp en ASF (derecha) en comparación con AK (izquierda)

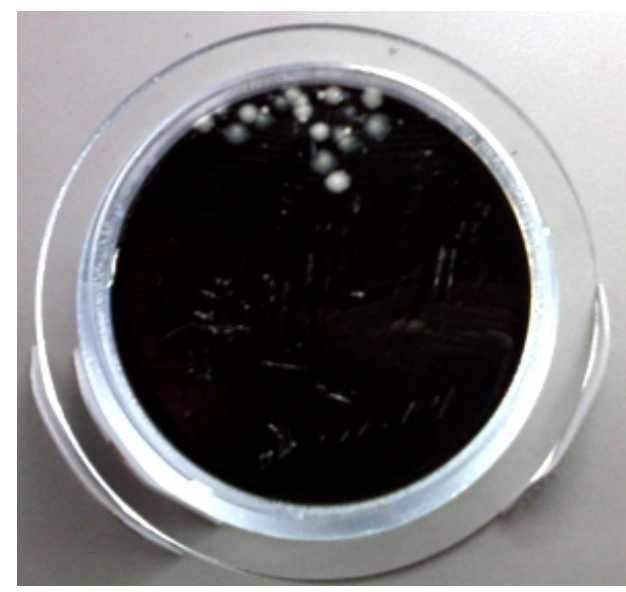

\section{DISCUSIÓN}

El método de filtración pasiva sobre el ASF permite el aislamiento, en muestras fecales de animales y humanos, de las especies tradicionales de Campylobacter y de otras especies menos comunes como Campylobacter fetus, Campylobacter jejuni subsp. Doylei, Campylobacter upsaliensis y Campylobacter insulaenigrae ${ }^{(34-37)}$. De esta forma, este método de aislamiento primario por filtración pasiva dispone de resultados costo-efectivos, selectividad microbiana y eficiencia diagnóstica, todo en un medio no selectivo y sin la necesidad de pretratamientos ${ }^{(38,39)}$.

En el presente estudio se demostró que el uso de ASF para el aislamiento de Campylobacter es tan o más eficaz como el uso del medios selectivos AK, resultado que coincide con estudios anteriores ${ }^{(28,40)}$. Igualmente, se han descrito mejores tasas de aislamiento cuando se utiliza la técnica de filtrado con cualquier medio de asilamiento para bacterias espiraladas incluyendo agar sangre ovina ${ }^{(41,42)}$.

En cuanto al rendimiento diagnóstico hubo diferencias estadísticamente significativas. Cabe resaltar que entre los pacientes positivos para Campylobacteriosis el 61,7\% (142 muestras) y 6,5\% (15 muestras) presentaron cultivo contaminado y falso negativo para AK, respectivamente (Tabla 1),

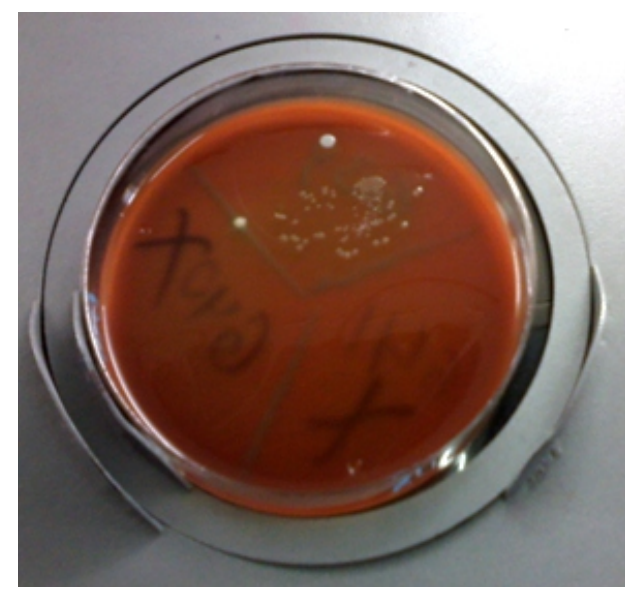

este problema dificulta el aislamiento de Campylobater y disminuye la eficacia y rendimiento del medio AK al no ser selectivo para enterobacterias en coprocultivos; a diferencia del método ASF donde la contaminación ocurre durante la extracción del filtro de membrana de sobre el agar no selectivo, aunque la tasa es minúscula (Figura 1). Este usual inconveniente podría deberse a la resistencia innata de las bacterias saprofitas, residente o transitoria, de los individuos, sin embargo, esta afirmación pierde validez al tratarse de pacientes pediátricos menores de 2 años de edad (promedio 8,92 meses) sin antibioticoterapia ${ }^{(43,44)}$. Consider utilis determinar la frecuencia de aislamientos contaminantes (bacterias patógenas en coinfecciones, bacterias saprofitas $\mathrm{y} / \mathrm{o}$ contaminantes no entéricos) y evaluar su resistencia antimicrobiana en base a la hipótesis del reservorio ${ }^{(45,46)}$.

El número de colonias fue visiblemente mayor en ASF lo cual facilitó la lectura y permitió un adecuado trasplante de agar a agar y/o pruebas diagnósticas adicionales (Figura 1).

El tiempo de crecimiento durante el aislamiento primario no tuvo diferencia significativa $(p=0,59)$. El cumplimiento estricto de las magnitudes físicas (tiempo y temperatura) favorecieron el crecimiento, así la tasa de crecimiento de Campylobacter se acrecienta en cualquier medio de aislamiento, si el 
tiempo de incubación se prolonga entre 48 y 72 horas a $42^{\circ} \mathrm{C}^{(33,41)}$. Además, el crecimiento a $42^{\circ} \mathrm{C}$ indica la presencia de un Campylobacter termófilo ( principalmente jejuni, aunque no exclusivamente) $)^{(33)}$.

La discriminación de especies juega un papel importante en el diagnóstico de infecciones por Campylobacter, ya que Campylobacter coli y jejuni son clínicamente indistinguibles, y son las especies más comunes asociados a ADD, aunque durante la última década se han observado emergencias significativas ${ }^{(47) .}$ La tasa estimada de asilamientos de Campylobacter jejuni fue de 1:3 respecto a Campylobacter no jejuni (Figura 2).

Estudios anteriores señalan que la prevalencia de Campylobacter no jejuni como agentes emergentes causante de ADD en niños y neonatos ${ }^{(48,49)}$.

Otro aspecto resaltante es el costo por prueba diagnóstica para Campylobacter. El precio de los medios de cultivo selectivos oscilan entre 216 y 320 USD, hasta dos veces más que ASF (agar y filtro). Al parecer, el costo-efectividad diagnóstico con el uso de Agares selectivos es bajo, ocasionando gran impacto económico hacia la institución. Concordamos con lo señalado por Steele y McDermontt: el ASF evita la necesidad de medios selectivos caros siendo accesible a laboratorios con escasos recursos $\mathrm{y} / \mathrm{o}$ en atención primaria de la salud $^{(40)}$.

Dos consideraciones finales son la probable transmisibilidad de la infección y el nivel de saneamiento básico. Sobre esto último, sustancial significado poseen las medidas generales sanitarioprofilácticas (la urbanización de localidades, organización del régimen sanitario, asistencia médica pediátrica, etc.) la mejora de estas condiciones reduciría de entre 12 y $45 \%$ la transmisibilidad de infecciones diarreicas, sobretodo en poblaciones de localidades desfavorables desde el punto de vista epidemiológico ${ }^{(50,51)}$. Con respecto a la probable transmisibilidad durante el cuidado postnatal la lactancia materna puede ser un potencial vehículo de transmisión de diarrea en madres con poca higiene doméstica, ineficaz lavado de manos, manipulación de alimentos contaminados y/o deficiencias en educación sanitaria ${ }^{(52)}$. Es desestimada la asociación de estos factores para ADD por Campylobacter, estimación que resultaría crucial, especialmente durante el período post natal y lactancia, donde las intervenciones oportunas pueden mejorar la salud y supervivencia de los infantes ${ }^{(53,54)}$.

En conclusión, el Agar Sangre con filtro presenta un mayor rendimiento diagnóstico que Agar Karmali para el aislamiento de Campylobacter, en un tiempo relativamente menor y demostrando ser más costoefectivo que el medio de asilamiento selectivo. Además, se aisló principalmente Campylobacter no jejuni en neonatos e infantes, donde acontecen la mayoría de infecciones. En eso contexto la evaluación de métodos es clave, para un diagnóstico oportuno, asequible y eficaz, dentro de un programa de garantía de la calidad que mejore la confiabilidad de los resultados emitidos por el laboratorio clínico.

Agradecimiento: Al equipo diagnóstico del Área de Microbiología del Hospital Nacional Docente MadreNiño San Bartolomé, a la Sociedad Peruana de Microbiología, y a los Lic. OR. Ronald Torres Martínez, Lic. TM. Víctor Rojas Zumarán por su soporte científico durante la realización de este estudio.

\section{REFERENCIAS BIBLIOGRÁFICAS}

1. Friedrich MJ. Climate Change Linked With Increase in Diarrheal Disease. JAMA2013; 309(19):1985.

2. PATH. Diarrehal disease: Solutions to defeat a global killer. Washington 2006.

3. World Health Organization (WHO), United Nations Children's Foundation (UNICEF). Joint statement on clinical management of acute diarrhoea. Geneva 2004.

4. World Health Organization. Global Water Supply and Sanitation Assessment, WSSCC/UNICEF.Geneva 2000; 2.

5. Black R, Lanata CF. Epidemiology of diarrheal in developing countries. 1st edition. New York: Raven Press. Ltd; 1995: 13-36.

6. Perales DM, Camiña M, Quiñones C. Infección por Campylobacter y Shigella como causa de Diarrea Aguda infecciosa en niños menores de dos años en el distrito de La Victoria, Lima-Perú. Rev Perú Med Exp Salud Publica 2002; 19(4).

7. Tam CC, Higgins CD, Neal KR, Rodrigues L, Millership S, 'OBrien $S$, et al. Chicken consumption and use of acid-supppressing medications as risk factors for Campylobacter enteriris, England. Emerg Infect Dis 2009; 15:1402-8.

8. Sheppard SK, Dallas JF, Strachan NJ, MacRae M, McCarthy ND, Wilson DJ, et al. Campylobacter genotyping to determine the source of human infection. Clin Infect Dis 2009;48:1072-8.

9. CDC. Vital signs: incidence and trends of infection with pathogens transmitted commonly trough food-foodborne disease active surveillance network, 10 U.S. sites, 1996-2010. MMWR Morb Mortal Wkly Rep 2011;60(22):749-55.

10. Rees HJ, Soudain ES, Gregson NA, Hughes AC. Campylobacter jejuni infection and Guillain-Barré syndrome. N Engl J Med. 1995; 333:1374-1379.

11. Matsusaki S, Katayama A, Yamagata H, Tanaka K, Nakamura T. Campylobacter enteritis in Japanese children. J Diar Dis Res. 1984; 2(2):88-9.

12. Dekeyser P, Gossuin-Detrain M, Butzler JP, Sternon J. Acute enteritis due to related Vibrio: first positive stool cultures. J Infect Dis. 1972; 125:390-392. 
13. Butzler, JP, Dekeyser P, Detrain M. et al. Related vibrios in stool. J Pediatr. 1973; 82: 493.

14. Bützler JP. Campylobacter infection in man and animals. Boca Raton: CRC Press; 1984.

15. Skirrow, MB. Campylobacter enteritis: a "new" disease. Br Med J 1977; 2:9-11.

16. Karmali MA, Simor AE, Roscoe M, Fleming PC, Smith SS, Lane J. J. Clin. Microbiol. 1986; 23:456-459.

17. Hunt JM, Abeyta C, Tran T. “Campylobacter”. In: FDA-CFSAN. Bacteriological analytical manual. 9th ed. Maryland: AOAC International; 2001:7.

18. Canduro PF, Mezzari A, Dias CAG. Stool culture: prevalence of pathogenic microorganisms in a private laboratory in Porto Alegre, Brazil. Rev Bras Patol Clin. 1987; 23:152-6.

19. Ruiz AP, Perea LB. Indicaciones y valoración clínica del urocultivo y coprocultivo. Medicine. 2010;10(49):3317-20.

20. CLSI publication M40-A2 -. Quality Control of Microbiological Transport Systems; Approved Standard-Second Edition Clinical and Laboratory Standards Institute, Wayne, PA,USA, 2014.

21. Prats PG, Mirelis OB, Muñoz BC, Rabella GN. Indicaciones del coprocultivo, aspectos prácticos. Medicine. 1998;7(74):34567.

22. Miller JL. A guide to specimen management in clinical microbiology. 2th ed. American Society for Microbiology. Washington, D.C. 1998.

23. Instituto de Salud Carlos III. Normas para el transporte de muestras con destino al centro nacional de microbiología. Madrid: Servicio Madrileño de Salud; 2002.

24. Crespo SD, Escribano GE, Lorente OS. Manual de Recogida, transporte y conservación de muestras. Laboratorio de microbiología. Albacete: Complejo Hospitalario de Albacete. 2010.

25. Engberg, J, On SL, Harrington CS, et al. Prevalence of Campylobacter, Arcobacter, Helicobacter, and Sutterella spp. in human fecal samples as estimated by a reevaluation of isolation methods for campylobacters. J Clin Microbiol. 2000; 38: 286-291.

26. Steele TW, McDermott SN. Technical note: the use of membrane filters applied directly to the surface of agar plates for the isolation of Campylobacter jejuni from faeces. Pathology. 1984;16:263-265.

27. PAHO. Zoonoses and Communicable Diseases Common to Man and Animals. Bacterioses and Mycoses. 3rd ed. Washington, D.C.: PAHO; 2001: 67-71.

28. Winn W, Allen S, Janda W. Koneman's Color Atlas and Textbook of Diagnostic Microbiology. 6th ed. Philadelphia: Lippincott Williams \& Wilkins; 2006: 373-79.

29. CLSI publication M35-A2 -. Abbreviated Identification of Bacteria and Yeast; Approved Guideline-Second Edition. Clinical and Laboratory Standards Institute, Wayne, PA,USA, 2008.

30. CLSI publication M100-S22 -. Performance Standards for Antimicrobial Susceptibility Testing; Twenty-second Informational supplement. Clinical and Laboratory Standards Institute, Wayne, PA,USA, 2012.

31. CLSI publication M45-A2 -. Methods for Antimicrobial Dilution and Disk Susceptibility Testing of Infrequently Isolated or Fastidious Bacteria; Approved Guideline-Second edition. Clinical and Laboratory Standards Institute, Wayne, PA, USA. 2010.

32. Larrosa HA, Ruiz PM, Aguilar BS. Utilidad del estudio de las heces para el diagnóstico y manejo de lactantes y preescolares con diarrea aguda. Salud Publica Mex. 2002;44:328-334.

33. Altman DG, Machin B, Bryant TN, Gardner MJ. Statistics with confidence. 2a ed. Bristol: BMJ Book; 2000.
34. Díaz C, Vizcaya L, Velasco J. Evaluación de un medio y la técnica de filtración para el aislamiento de Campylobacter sp. en un grupo de riesgo. Rev Fac Farm. 2003; 45 (1): 14-18.

35. Fernández H, Vera F, Villanueva MP, García A. Occurrence of Campylobacter species in healthy well-nourished and malnourished children. Braz J Microbiol. 2008;39:56-8.

36. Fernández H, Vera F, Villanueva MP. Especies de Arcobacter y Campylobacter en aves y mamíferos del sur de Chile. Arch Med Vet. 2007;39(2):163-165.

37. Modolo JR, Giuffrida R. Campylobacter upsaliensis isolated from young dogs with and without diarrea. Rev Soc Bras Med Trop. 2004; 37(1):72-73.

38. Patiño GL. Estudio comparativo entre la microscopia convencional y el método de cultivo con microfiltros para la identificación de Campylobacter sp en muestras fecales de pacientes del HNGAl durante el $2^{\circ}$ semestre del 2002. [Tesis]. Lima: Universidad Nacional Mayor de San Marcos. Facultad de Medicina Humana; 2002.

39. Pinto AM. Aplicación del Método de Filtración para la Detección de Campylobacter spp en Heces.

40. Fundación de Tecnología de Alimentos, Sucre - Bolivia; 1999.

41. Steel TW, McDermont SN. Technical note: The use of membrane filters applied directly to the surfaces of agar plates tor the isolation of Campylobacter jejuni from feces. Pathology. 1984; 16:263-265.

42. Gossens H, Vlaes L, Galand IM, C Van den Borre, Butzler JP. Semisolid blood-free selective-motility medium for the isolation of campylobacters from stool specimens. J Clin Microbiol. 1989;27(5):1077-80.

43. Endtz HP, Ruijs GJ, Zwinderman AH, van der Reijden T, Biever M, Mouton RP. Comparison of six media, including a semisolid agar, for the isolation of various Campylobacter species from stool specimens. J Clin Microbiol. 1991; 29(5):1007-10.

44. Ash C. Antibiotic resistance: The new apocalypse? Trends in Microbiology. 1996;4(10):371-372.

45. van der Waaji, D. Colonization resistance of the digestive tract in conventional and antibiotic treated mice. J Hydrol. 1971 69,405-411.

46. Prescott J, Baggot J, Walter R. Terapéutica Antimicrobiana en Medicina Veterinaria. 3ra Edición. Buenos Aires: Intermédica; 2002.

47. Ruppé E, Andremont A. Causes, consequences, and perspectives in the variations of intestinal density of colonization of multidrug-resistant enterobacteria. Front. Microbiol. 2013; 4:129.

48. Murray P. R., Baron E. H., Pfaller M. A., Tenover F. C. and Yolken R. H., (Ed.), Manual of Clinical Microbiology, 6th Ed., American Society for Microbiology, Washington, D.C. 1995.

49. World Health Organization. The increasing incidence of human Campylobacteriosis. Report and Proceedings of a WHO Consultation of Experts. Copenhagen. WHO/CDS/ CSR/APH/2000;4: 2001

50. Castillo M, Gómez F, Laos M, Salinas M. Campylobacter spp en pacientes con cuadro diarreico que acudieron a Hospitales de la ciudad de Ica, Perú. Marzo-mayo 1999. Rev Peru Med Exp Salud Publica. 2003;20(3):S6.

51. World Health Organization. Water, Sanitation and Hygiene Links to Health: Facts and Figures. Geneva 2004.

52. Nósov SD. Enfermedades infecciosas infantiles. Primera ed. URSS: Editorial Mir.; 1980:363.

53. UNICEF. Breastfeeding: Foundation for a Healthy Future. New York: UNICEF; 1999.

54. Joy EL, Simon C, Jelka Z. 4 Million Neonatal Deaths: When? Where? Why? The Lancet. 2005; 365(9462): 891-900. 
Fuentes de financiamiento

Este artículo ha sido financiado por los autores.

Conflictos de interés

Recibido: 08 de febrero de 2016

Los autores declaran no tener ningún conflicto de interés.

Correspondencia:

Jeel J. Moya Salazar

Dirección: Jr. Pacifico 957. Lima 07. 51001 Lima, Perú

Teléfono: +051 1986014954

Correo electrónico: jeelms@outlook.com, jeel.moya.s@upch.pe

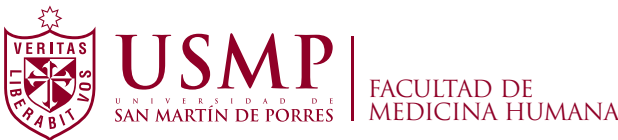

\section{HORIZONTE MÉDICO}

Difundiendo la Investigación, más allá; de nuestras fronteras
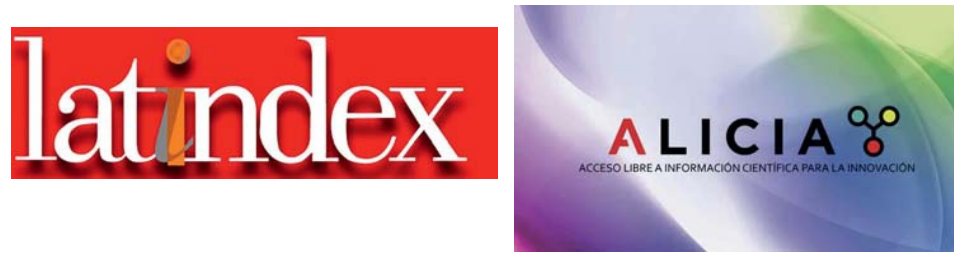

LILACS

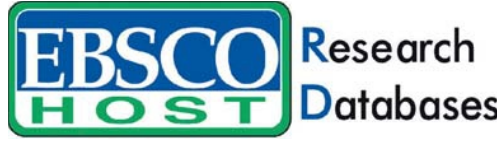

REPEBIS

Red Peruana de Biblioteca en Salud
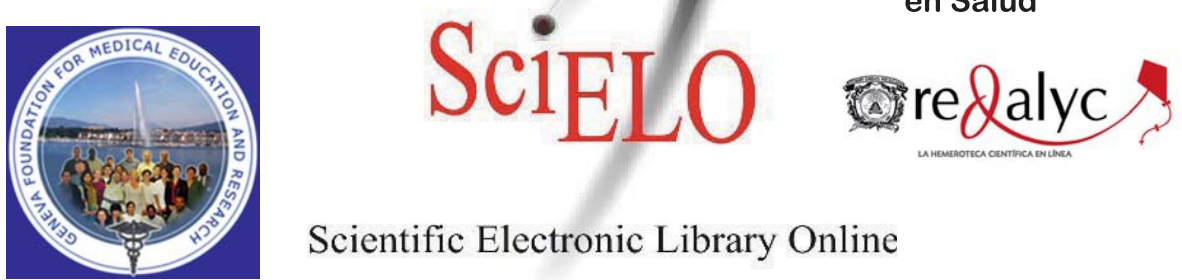

Scientific Electronic Library Online
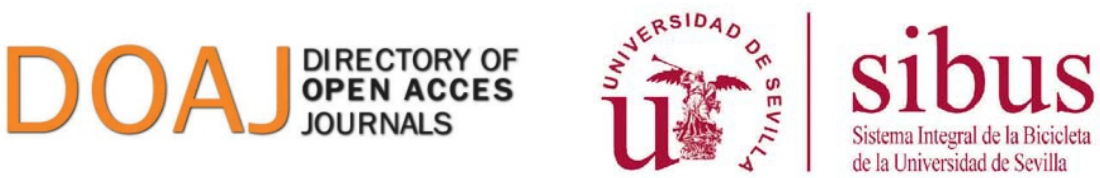